\title{
Expression of a protease-resistant insulin-like growth factor-binding protein-4 inhibits tumour growth in a murine model of breast cancer
}

\author{
AJ Ryan', S Napoletano', PA Fitzpatrick', CA Currid', NC O'Sullivan' and JH Harmey*,I \\ 'Molecular and Cellular Therapeutics, Royal College of Surgeons in Ireland, 123 St Stephens Green, Dublin 2, Ireland
}

\begin{abstract}
BACKGROUND: Insulin-like growth factor I (IGFI) promotes breast cancer and disease progression. Bioavailability of IGFI is modulated by IGF-binding proteins (IGFBPs). IGFBP4 inhibits IGFI activity but cleavage by pregnancy-associated plasma protein-A (PAPP-A) protease releases active IGFI.

METHODS: Expression of IGF pathway components and PAPP-A was assessed by western blot or RT-PCR. IGFBP4 (dBP4) resistant to PAPP-A cleavage, but retaining IGF-binding capacity, was used to block IGF activity in vivo. 4TI.2 mouse mammary adenocarcinoma cells transfected with empty vector, vector expressing wild-type IGFBP4 or vector expressing dBP4 were implanted in the mammary fat pad of BALB/c mice and tumour growth was assessed. Tumour angiogenesis and endothelial cell apoptosis were assessed by immunohistochemistry.

RESULTS: 4TI.2 cells expressed the IGFIR receptor and IGFBP4. PAPP-A was expressed within mammary tumours but not by 4TI.2 cells. Proliferation and vascular endothelial growth factor (VEGF) production by 4TI.2 cells was increased by IGFI (E3R) (recombinant IGFI resistant to binding by IGFBPs) but not by wild-type IGFI. IGFI-stimulated microvascular endothelial cell proliferation was blocked by recombinant IGFBP4. 4TI .2 tumours expressing dBP4 grew significantly more slowly than controls or tumours expressing wild-type IGFBP4. Inhibition of tumour growth by dBP4 was accompanied by the increased endothelial cell apoptosis.
\end{abstract}

CONCLUSION: Protease-resistant IGFBP4 blocks IGF activity, tumour growth and angiogenesis .

British Journal of Cancer (2009) I 0I, 278-286. doi:10.1038/sj.bjc.6605 I4I www.bjcancer.com

Published online 16 June 2009

(c) 2009 Cancer Research UK

Keywords: insulin-like growth factor; insulin-like growth factor-binding protein-4; pregnancy-associated plasma protein A; angiogenesis; breast cancer

Insulin-like growth factors (IGFs) are small potent mitogenic proteins and there is significant evidence that IGF1 promotes breast cancer and plays a role in disease progression (Hankinson et al, 1998). The type I insulin-like growth factor receptor (IGF1R) is overexpressed by many breast cancer cell lines and high levels of IGF1 are associated with poor prognosis in breast cancer (Huynh et al, 1993; Peyrat et al, 1993). IGF1 (or 2) binding results in autophosphorylation of IGF1R and activation of PI3K (phosphatidylinositol-3-kinase), Akt and MAPK (mitogen-activated protein kinase) (LeRoith et al, 1995; Saltiel and Kahn, 2001). The insulin-like growth factor-binding proteins (IGFBPs) modulate the biological activity of IGF, either inhibiting or potentiating its effects. At least six IGFBPs have been identified to date. Proteolysis of the IGFBPs plays a vital role in regulating IGF activity (Fowlkes et al, 1997) releasing biologically active IGF (Clemmons et al, 1998).

IGFBP4 inhibits the activity of IGF1 and does not enhance the actions of IGF1 under any conditions (Jones and Clemmons, 1995). IGFBP4 is produced mainly in the liver but many other tissues,

*Correspondence: Dr JH Harmey; E-mail: jharmey@rcsi.ie Received 8 August 2008; revised 19 March 2009; accepted I 8 May 2009; published online 16 June 2009 especially neoplastic tissue, produce it (Korc-Grodzicki et al, 1993; Lewinski et al, 2004).

IGFBP4 protease activity has been described in a variety of cell types including placental tissue, fibroblasts and osteoblasts (Conover et al, 1993; Durham et al, 1995). The IGFBP4 protease is a metalloprotease, which cleaves IGFBP4 into 18 and $14 \mathrm{kDa}$ fragments and its activity is IGF-dependent (Conover et al, 1995). It was later identified as pregnancy-associated plasma protein-A (PAPP-A) (Lawrence et al, 1999) with a cleavage site at $\mathrm{Met}^{135}$ Lys $^{136}$ in the mature human IGFBP4 protein (Conover et al, 1995; Chelius et al, 2000). Although IGFBP4 inhibits the actions of IGF1, proteolytic cleavage by PAPP-A in vivo releases biologically active IGF from IGFBP4. In addition to PAPP-A, prostatic kallikreins, hK2 and hK3 (prostate specific antigen), can also cleave IGFBP4 (Rehault et al, 2001).

We established that 4T1.2 mouse mammary adenocarcinoma cells expressed IGF1R and were responsive to IGF1. We anticipated that wild-type IGFBP4 would be unable to block IGF1 activity in 4T1.2 mammary tumours in vivo because of the presence of active PAPP-A in mammary tissue. We hypothesised that a proteaseresistant IGFBP4, however, would inhibit 4T1.2 tumour growth by binding IGF1 rendering it biologically inactive even in the presence of PAPP-A. In the orthotopic 4T1.2 breast cancer model, we 
demonstrate that the expression of a protease-resistant IGFBP4, where the PAPP-A cleavage site has been mutated without altering its IGF-binding capacity, inhibited 4T1.2 tumour growth. PAPP-A sensitive wild-type IGFBP4 had no significant effect on tumour growth. Inhibition of tumour growth was accompanied by increased endothelial cell apoptosis within the tumours.

\section{MATERIALS AND METHODS}

\section{Cell culture}

4T1.2 cells, murine mammary adenocarcinoma cells that preferentially metastasise to bone, were a gift from Robin Anderson (Peter MacCallum Cancer Centre, Australia.) (Lelekakis et al, 1999). 4T1.2 cells were maintained in Roswell Park Memorial Institute (RPMI) 1640 medium, supplemented with $10 \%$ (v/v) fetal calf serum (FCS), $100 \mathrm{U} \mathrm{ml}^{-1}$ penicillin, and $100 \mu \mathrm{g} \mathrm{ml}^{-1}$ streptomycin sulphate. MCF7 human breast adenocarcinoma cells were maintained in Eagles Minimum Essential Medium supplemented with $10 \%$ (v/v) FCS. Human embryonic kidney (HEK) 293 cells were maintained in high-glucose Dulbecco's Modified Eagle's Medium (DMEM) supplemented with $10 \%$ (v/v) FCS. MC3T3 osteoblasts were differentiated for 7 days in $\alpha$ MEM containing $10 \%$ $(\mathrm{v} / \mathrm{v})$ FCS supplemented with $10 \mathrm{~mm} \beta$-glycerol phosphate and $50 \mu \mathrm{g} \mathrm{ml}^{-1}$ ascorbic acid. Primary dNeo-Neonatal human dermal microvascular endothelial cells (MVECs) were purchased from Lonza (Lonza Workingham Ltd, Workingham, UK) and maintained in complete EGM-2MV Microvascular Endothelial Cell Growth Medium-2 (Lonza Workingham Ltd, Workingham, UK) (containing gentamicin, 5\% (v/v) FCS, hEGF, hydrocortisone, VEGF, hFGF-B, $\mathrm{R}^{3}$-IGF-1 and ascorbic acid). All cell lines were cultured at $37^{\circ} \mathrm{C}$ in an atmosphere of $5 \% \mathrm{CO}_{2}$ in air.

\section{Effect of IGF1 on $4 \mathrm{~T} 1.2$ cell proliferation}

$10^{3} 4 \mathrm{~T} 1.2$ cells per well were plated in triplicate in 96-well plates, allowed to adhere overnight, then treated with recombinant mouse IGF1 (R\&D Systems, Abingdon, UK) or IGF1 (E3R) (Upstate, Cell Signaling Solutions, Lake Placid, NY, USA) for $48 \mathrm{~h}$ at $0-$ $100 \mathrm{ng} \mathrm{ml}^{-1}$. Following treatment, cell proliferation was assessed using a colourimetric cell proliferation BrdU ELISA Kit (Roche Diagnostics, Burgess Hill, UK). Proliferation was expressed relative to untreated controls, which were taken as $100 \%$.

\section{Effect of IGF1 on MVEC proliferation}

1500 MVEC cells per well were plated in duplicate in 96-well plates, allowed to adhere overnight, then treated for $96 \mathrm{~h}$ in complete EGM-2MV medium with $50 \mathrm{ng} \mathrm{ml}^{-1}$ recombinant human IGF-1 alone or in combination with $200 \mathrm{ng} \mathrm{ml}^{-1}$ recombinant human IGFBP4, or with $10 \mathrm{ng} \mathrm{ml}^{-1}$ recombinant human VEGF alone (IGF1, IGFBP4 and VEGF from R\&D Systems). Following treatment, $10 \mu \mathrm{l}$ of $5 \mathrm{mg} \mathrm{ml}^{-1}$ MTT reagent (3-[4,5-Dimethyl-2thiazolyl]-2,5-diphenyl-2H-tetrazolium bromide, Sigma-Aldrich, St Louis, MO, USA) was added to each well for $4 \mathrm{~h}$ at $37^{\circ} \mathrm{C}$. Culture medium was removed, MTT was solubilised in $100 \mu \mathrm{l}$ dimethyl sulphoxide (Sigma-Aldrich) and optical density at $570 \mathrm{~nm}$ was recorded. Proliferation was expressed relative to untreated controls, which were taken as $100 \%$.

\section{Effect of IGF1 on VEGF expression}

$10^{3}$ cells per well were plated in triplicate in 96-well plates, allowed to adhere overnight, then treated with IGF1 (R\&D Systems) or IGF1 (E3R) (Upstate, Cell Signaling Solutions) in serum-free medium for $48 \mathrm{~h}$ at $0-100 \mathrm{ng} \mathrm{ml}^{-1}$. Culture supernatants were collected and VEGF $_{165}$ expression was assayed by ELISA (R\&D Systems). Total cell protein was measured by BCA assay (Pierce,
Rockford, IL, USA). VEGF $_{165}$ was expressed as $\mathrm{pg} \mathrm{mg}^{-1}$ cell protein.

\section{Western blot analysis}

A total of $400 \mathrm{mg}$ of normal mammary fat pad tissue and $4 \mathrm{~T} 1.2$ mammary tumours was finely chopped on ice in $500 \mu \mathrm{l}$ of RIPA buffer (25 mM Tris-HCl, pH 7.4, $150 \mathrm{~mm} \mathrm{NaCl}, 1 \%$ (v/v) NP-40, 1\% (w/v) SDS, 2 mm EDTA, 1/100 dilution protease inhibitor cocktail (Sigma-Aldrich)), placed on ice for $30 \mathrm{~min}$, disrupted three times (10 s each) at 12000 r.p.m. with a Polytron homogeniser (PT1600E, Kinematica, Switzerland) and incubated on ice for a further $30 \mathrm{~min}$. Homogenate was cleared by centrifuging at $12000 \mathrm{~g}$ for $1 \mathrm{~h}$ at $4^{\circ} \mathrm{C}$.

Conditioned medium was concentrated using $3 \mathrm{kDa}$ Amicon centrifugal filters (Millipore, Billerica, MA, USA). For cell lysates, cells were washed twice with PBS and lysed in RIPA buffer. Total protein was quantified using the BCA assay (Pierce). A total of $25 \mu \mathrm{g}$ of protein was fractionated by $12 \%$ SDS-PAGE or using $4-20 \%$ Precise precast gels (Pierce) and transferred to nitrocellulose membranes. Membranes were blocked in TBST $(10 \mathrm{~mm}$ Tris-HCl, pH 7.4, $100 \mathrm{~mm} \mathrm{NaCl}, 0.1 \%$ (v/v) Tween-20) containing $5 \%(\mathrm{w} / \mathrm{v})$ non-fat powdered milk for $1 \mathrm{~h}$ and incubated overnight at $4{ }^{\circ} \mathrm{C}$ with either 1:4000 rabbit anti-human IGFBP4 (Upstate) in TBST/5\% (w/v) non-fat powdered milk or 1:1000 rabbit antihuman IGFIR $\beta$ (Cell Signaling Technology Inc., Danvers, MA, USA) in TBST/5\% (w/v) BSA (bovine serum albumin). Both antibodies also recognise the mouse protein. Membranes were washed six times with TBST, incubated with $1: 2000$ horseradish peroxidase conjugated anti-rabbit antibody (DAKO, Glostrup, Denmark) in TBST/5\% (w/v) non-fat powdered milk, for $1 \mathrm{~h}$, then washed six times with TBST. Antibody complexes were detected using Supersignal West Pico Chemiluminescent Substrate (Pierce).

\section{PAPP-A RT - PCR}

Total RNA was isolated using TRIzol reagent (Invitrogen, Paisley, UK) according to the manufacturer's instructions. Briefly, samples were homogenized in TRIzol reagent, RNA was separated using chloroform and precipitated with isopropanol. RNA pellet was then washed with ethanol and dissolved in RNase-free water. SuperScript III First-Strand Synthesis System for RT-PCR (Invitrogen, Paisley, UK) was used to generate cDNA for PCR. PAPP-A cDNA was amplified using $50 \mathrm{pM}$ forward $\left(5^{\prime}\right.$ CACTTGGGCGGTATTGTCTT- $3^{\prime}$ ) and reverse (5'-TGGGTTGGTATCATTGCAGA- $3^{\prime}$ ) primers, which produce a $198 \mathrm{bp}$ product from mouse PAPP-A. A total of 40 cycles of $94^{\circ} \mathrm{C}$ for $45 \mathrm{~s}, 56^{\circ} \mathrm{C}$ for $45 \mathrm{~s}$, $72^{\circ} \mathrm{C}$ for $45 \mathrm{~s}$ were carried out using AmpliTaq polymerase (Applied Biosystems, Foster City, CA, USA). $\beta$-Actin was amplified using mouse $\beta$-actin-specific primers (Stratagene, La Jolla, CA, USA) by 35 cycles of $94^{\circ} \mathrm{C}$ for $45 \mathrm{~s}, 60^{\circ} \mathrm{C}$ for $45 \mathrm{~s}, 72^{\circ} \mathrm{C}$ for $45 \mathrm{~s}$.

\section{IGFBP4 cloning}

Wild-type rat IGFBP4 (BP4) and protease-resistant rat IGFBP4 (dBP4) clones in pBluescript SK + - pW12 and pSMP-8, respectively - were a gift from Dr James Fagin, (Division of Endocrinology, University of Cincinnati College of Medicine and the Children's Hospital Medical Centre, Cincinnati, OH, USA). In dBP4, the PAPP-A cleavage site of IGFBP4, KHMAKVRDRSKMK, was mutated to AAMAAVADASAMA, preventing proteolytic cleavage without affecting IGF-binding capacity (Zhang et al, 2002). BP-4 and dBP-4 were excised with EcoRI, ligated into pCMVScript and verified by sequencing. 4T1.2 cells were transfected with pCMV, pCMV-BP4 or pCMV-dBP4 using FuGENE 6 (Roche Diagnostics). 


\section{PAPP-A digestion}

$1.5 \times 10^{5}$ HEK293 cells per well were plated in six-well plates, allowed to adhere overnight and transfected with pCMV, pCMVBP4 or pCMV-dBP4 using Effectene (Qiagen, Sussex, UK). Following transfection, cells were maintained in serum-free medium for $48 \mathrm{~h}$. Conditioned medium was concentrated using $3 \mathrm{kDa}$ Amicon centrifugal filters (Millipore) and $25 \mu \mathrm{g}$ total protein in $20 \mu \mathrm{l}$ was incubated with IGF2 $\left(10 \mu \mathrm{g} \mathrm{ml}^{-1}\right)$ (R\&D Systems) and rhPAPP-A $\left(500 \mathrm{ng} \mathrm{ml}^{-1}\right)$ for $24 \mathrm{~h}$ at $37^{\circ} \mathrm{C}$. rhPAPP-A was a gift from Dr Claus Oxvig, University of Aarhus as described (Overgaard et al, 2000). Following digestion, IGFBP4 cleavage was analysed by western blot.

\section{In vivo model}

Animals were housed in a licensed biomedical facility (RCSI, Beaumont Hospital) and had ad libitum access to animal chow and water. All procedures were subjected to institutional ethics review, carried out under animal licence guidelines of the Department of Health and Children, Ireland and in accordance with the UK Co-ordinating Committee on Cancer Research (UKCCCR) Guidelines for the Welfare of Animals in Experimental Neoplasia (1998). $5 \times 10^{4} 4 \mathrm{~T} 1.2$ cells transfected with pCMV, pCMV-BP4 or pCMV-dBP4 were implanted into the mammary fat pad of 12-weekold female $\mathrm{BALB} / \mathrm{c}$ mice. Tumours were measured with calipers on alternate days and the mean tumour diameter (MTD) (square root of the product of length by breadth) was calculated. In the first experiment, mice in all groups were killed when the controls reached an MTD of $17 \mathrm{~mm}$ in accordance with UKCCCR Guidelines (1998). Primary tumours were excised, and snap-frozen in OCT (Leica, UK). In the second experiment, individual animals in each group were killed when their tumour reached an MTD of $17 \mathrm{~mm}$.

\section{Immunohistochemistry}

Sections $(7 \mu \mathrm{m})$ were cut from tissues preserved in OCT compound, fixed in cold acetone for $5 \mathrm{~min}$, cold acetone: chloroform
$(1: 1)$ for $5 \mathrm{~min}$ and cold acetone for $5 \mathrm{~min}$ followed by three washes in PBS for $5 \mathrm{~min}$ each.

Microvessel density was assessed as described previously (Harmey et al, 2002). In brief, following staining with an antibody to MECA32, an endothelial cell-specific marker, vessels were counted in five high power fields of view (h.p.f.) per section $(\times 400$ magnification, $(\times 40$ objective and $\times 10$ ocular $)$ ) from five mice per group.

Apoptotic endothelial cells were identified with CD31 (to identify endothelial cells) and TUNEL (to identify apoptotic cells) staining. Sections fixed as above, were incubated with rat antimouse CD31 (BD-Pharmingen, San Jose, CA, USA) 1:400 in protein block $(5 \%(\mathrm{v} / \mathrm{v})$ normal horse serum, $1 \%(\mathrm{v} / \mathrm{v})$ normal goat serum in PBS) overnight at $4^{\circ} \mathrm{C}$, then washed three times in PBS. Sections were incubated with protein block for $10 \mathrm{~min}$, then incubated with Texas Red conjugated goat anti-rat IgG (West Grove, PA, USA) diluted $1: 200$ in protein block for $90 \mathrm{~min}$, and washed four times. Apoptosis was assayed using the DeadEnd Fluorometric TUNEL System (Promega, Madison, WI, USA) according to manufacturers instructions. Sections were then mounted using Prolong Gold Antifade Reagent with DAPI (Molecular Probes, Carlsbad, CA, USA). Apoptotic endothelial cells were counted in five high power fields of view (h.p.f.) per section ( $\times 400$ magnification, $(\times 40$ objective and $\times 10$ ocular $)$ ) from at least three mice per group.

Immunohistochemistry data were analysed by ANOVA with Bonferroni post hoc correction.

\section{RESULTS}

IGF1R, IGFBP4 and PAPP-A expression by 4T1. 2 cells and 4T1.2 mammary fat pad tumours

4T1.2 cells express the IGF1R, identified by western blotting with an antibody specific for the IGF1R $\beta$ subunit (Figure 1A). Cell lysates from MCF7 human breast cancer cells, which have previously been shown to express IGF1R, were used as a positive
A

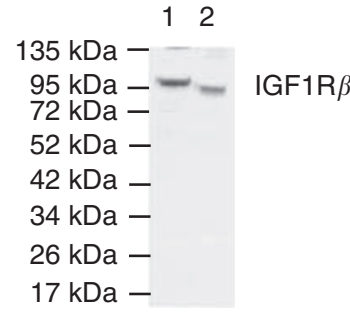

B

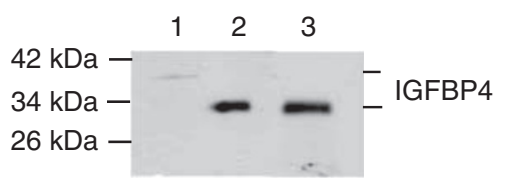

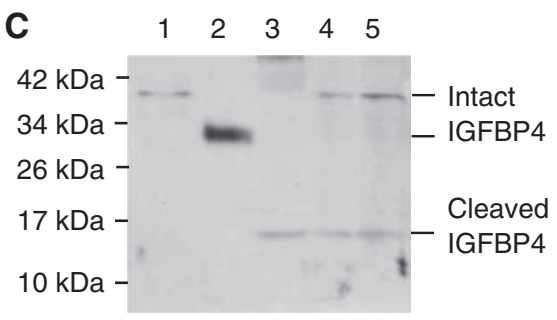

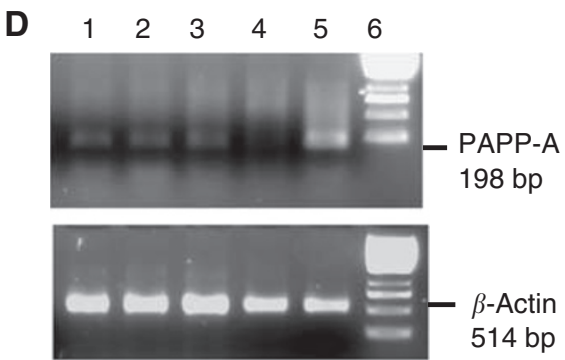

Figure I Expression of IGFIR, IGFBP4 and the IGFBP4 protease, PAPP-A. (A) Western blot analysis of IGF IR $\beta$ in 4TI.2 cell lysate (lane I). Cell lysate from MCF7 cells is shown in lane 2 as positive control. Positions of molecular weight markers are indicated (kDa). (B) Western blot analysis of IGFBP4 expression in cell lysate (lane I) and conditioned medium (lane 2) from 4TI.2 cells. Recombinant human IGFBP4 (I0 ng) is shown in lane 3 as a positive control. Positions of molecular weight markers are indicated (kDa). (C) Western blot analysis of IGFBP4 in normal mammary fat pad (lane 3) and 4TI.2 mammary fat pad tumours (lanes 4 and 5). IGFBP4 expression in cell lysate (lane I) and conditioned medium (lane 2) from 4TI.2 cells is shown for reference. Positions of molecular weight markers are indicated $(\mathrm{kDa})$. (D) RT-PCR of PAPP-A. PAPP-A (top panel) was amplified by RT-PCR from cDNA prepared from the 4TI.2 mammary fat pad tumours (lanes I, 2 and 3), 4TI.2 cells (lane 4) and MC3T3 mouse osteoblasts (lane 5). Molecular weight markers (I Kb ladder) are shown in lane 6. $\beta$-Actin (lower panel) was amplified from all samples to control for sample quality. 
control (Hailey et al, 2002). The antibody used recognises both the mouse and human $\beta$-subunit of IGF1R. The predicted molecular weight for the human $\beta$-subunit is $95 \mathrm{kDa}$ with the mouse subunit migrating slightly higher. 4T1.2 cells expressed IGFBP4, most of which is secreted (Figure 1B). Cellular IGFBP4 migrated slightly slower than the secreted IGFBP4, presumably because of the presence of the secretion signal. IGFBP4 expression in normal mammary fat pad tissue and 4T1.2 mammary fat pad tumours was then examined (Figure 1C). Cell lysate and conditioned medium from $4 \mathrm{~T} 1.2$ cells was run alongside these samples to allow size alignment (lanes 1 and 2, respectively). Intact cell-associated IGFBP4 as well as IGFBP4 cleavage fragments were identified in both normal mammary fat pad tissue (lane 3) and 4T1.2 mammary tumours (lanes 4 and 5). PAPP-A cleaves IGFBP4 at a single site into two fragments of 18 and $14 \mathrm{kDa}$ (Conover et al, 1995). The $\mathrm{N}$-ter and C-ter cleavage fragments co-migrated as previously shown (Laursen et al, 2001). The presence of IGFBP4 cleavage fragments suggested the presence of active PAPP-A protease in these tissues. PAPP-A expression by $4 \mathrm{~T} 1.2$ cells and in $4 \mathrm{~T} 1.2$ mammary fat pad tumours was assessed by RT - PCR (Figure 1D). cDNA from differentiated mouse osteoblast MC3T3 cells previously shown to express PAPP-A was used as positive control (Bunn et al, 2004). Although 4T1.2 cells did not express PAPP-A, it was expressed within normal mammary fat pad tissue as well as 4T1.2 mammary fat pad tumours in vivo, suggesting that PAPP-A is produced by host cells within the tumours.

\section{Cell proliferation and VEGF expression in response to IGF1}

As 4T1.2 cells expressed IGF1R, cell proliferation in response to the IGF1 ligand was examined (Figure 2A). IGF1 had no effect on cell proliferation. However, IGF1 (E3R), a 70 amino-acid IGF1 analogue with substitution of Arg for Glu at position 3 with reduced affinity for all IGFBPs, significantly increased cell proliferation at doses $\geq 60 \mathrm{ng} \mathrm{ml}^{-1}$. The effect of biologically active IGF1 on the expression of the angiogenic factor, VEGF was then examined. IGF1 at doses $\geq 50 \mathrm{ng} \mathrm{ml}^{-1}$ had no significant effect on $V_{E G F} F_{165}$ expression, while IGF1(E3R) significantly increased expression of $\mathrm{VEGF}_{165}$ at doses $\geq 50 \mathrm{ng} \mathrm{ml}^{-1}$ (Figure 2B). These data indicate that IGFBP4 (and/or other IGFBPs) secreted by 4 T1.2 cells blocked IGF1 activity. As biologically active IGF1 increased VEGF production by 4 T1.2 cells and has previously been shown to increase proliferation of primary HUVEC (human umbilical vein endothelial cells) (Wu et al, 2004), we examined the effect of IGF1 on proliferation of primary human dermal MVECs in the absence or presence of recombinant IGFBP4 (Figure 2C). IGF1 at $50 \mathrm{ng} \mathrm{ml}^{-1}$ increased MVEC proliferation, an effect that was blocked by $200 \mathrm{ng} \mathrm{ml}^{-1}$ rhIGFBP4.

\section{Protease-resistant IGFBP4 inhibits 4T1.2 tumour growth}

The in vitro data suggested that IGFBP4 would inhibit IGF1stimulated growth of 4T1.2 tumours by blocking its effects on tumour cell and endothelial cell proliferation and VEGF production. In vivo, IGFBP4 is cleaved by the protease PAPP-A to release biologically active IGF1. We therefore examined the effects of wildtype IGFBP4 and protease-resistant IGFBP4 expression on tumour growth in an orthotopic model of breast cancer. Protease-resistant IGFBP4 and wild-type IGFBP4 were subcloned into pCMVScript under the control of the CMV constitutive promoter generating pCMV-dBP4 and pCMV-BP4, respectively. Figure 3A shows IGFBP4 expression by transfected $4 \mathrm{~T} 1.2$ cells. The antibody used recognises both wild-type- and protease-resistant IGFBP4. Clones marked with an asterisk were used for in vivo studies. As we had no way of differentiating endogenous and exogenous IGFBP4 expression in 4T1.2 cells, pCMV, pCMV-BP4 and pCMVdBP4 were transfected into HEK293 cells which do not express
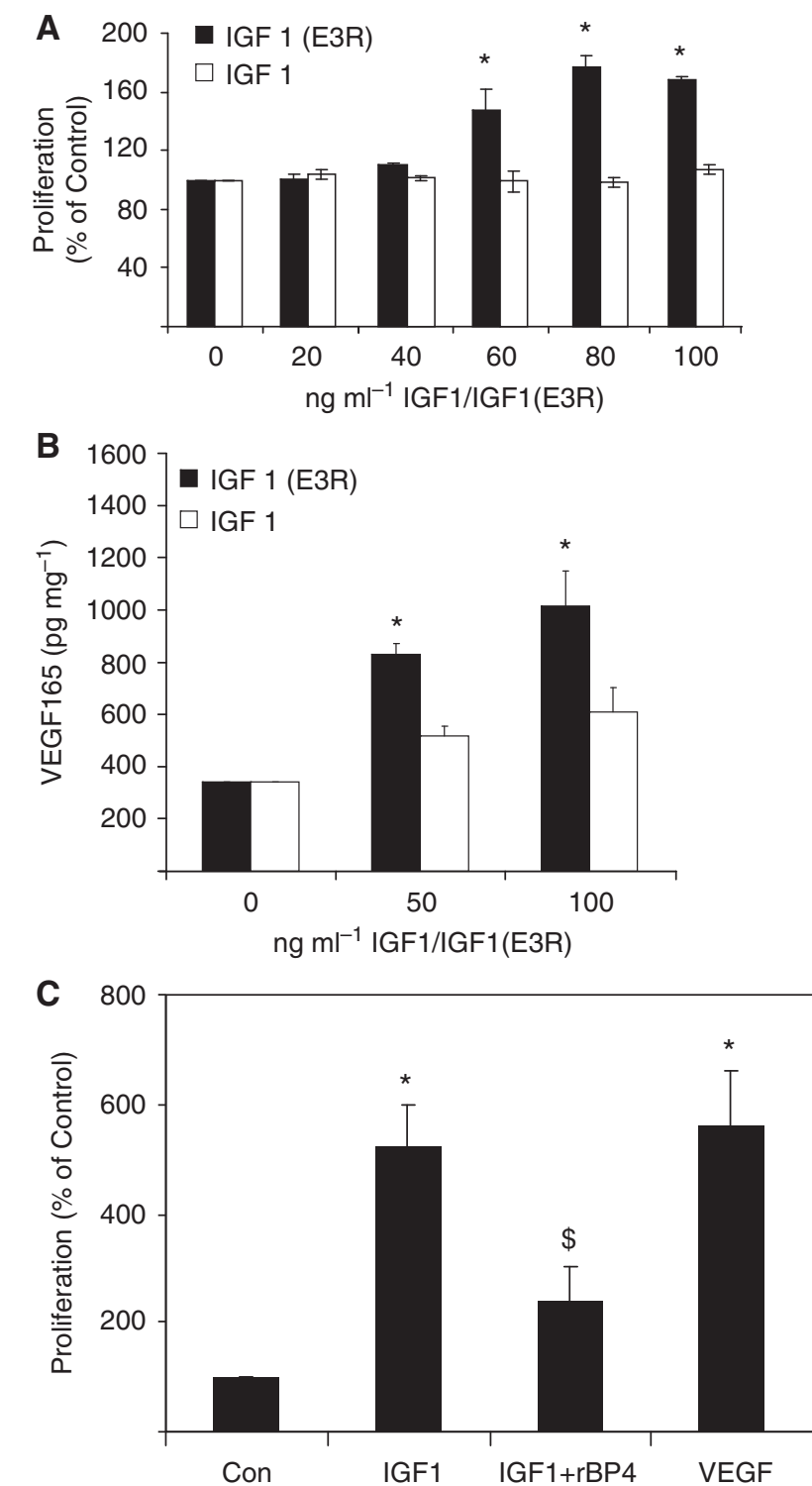

Figure 2 Effect of IGFI on 4TI.2 tumour cells and MVECs. (A) 4TI.2 cell proliferation in response to IGF I or IGF I (E3R). Cells were treated in triplicate for $48 \mathrm{~h}$ and proliferation assayed by BrdU incorporation. Proliferation is expressed as \% of control where control is taken as 100\%. Data $(n=3)$ expressed as mean \pm s.e.m. and analysed by ANOVA with LSD post hoc correction. ${ }^{*} P<0.05$ vs Control. (B) VEGF expression by 4TI.2 cells in response to IGF I or IGF I (E3R). Cells were treated for $48 \mathrm{~h}$ in triplicate and VEGF 165 measured by ELISA. Total cell protein was measured by BCA. Data $(n=3)$ expressed as mean \pm s.e.m. and analysed by ANOVA with Scheffe post hoc correction. $* P<0.05$ vs control. (C) Effect of IGFBP4 on IGFI-induced MVEC proliferation. Cells were treated in triplicate for $96 \mathrm{~h}$ with $50 \mathrm{ng} \mathrm{ml}^{-1}$ IGFI alone or in combination with $200 \mathrm{ng} \mathrm{ml}^{-1}$ IGFBP4 and proliferation assessed by MTT assay. Cells were treated with $10 \mathrm{ng} \mathrm{ml}^{-1}$ recombinant VEGF as positive control. Proliferation is expressed as \% of control where control is taken as $100 \%$. Data $(n=3)$ expressed as mean \pm s.e.m. and analysed by ANOVA with Tukey-Kramer post hoc correction. ${ }^{*} P<0.05$ vs control; ${ }^{\$} P<0.05$ vs IGFI.

IGFBP4 (data not shown). Conditioned medium collected from these cells was treated with rhPAPP-A $\left(500 \mathrm{ng} \mathrm{ml}^{-1}\right)$ in the presence of IGF2 $\left(10 \mu \mathrm{g} \mathrm{ml}^{-1}\right)$. Figure 3B shows that dBP4 is resistant to PAPP-A cleavage (lane 6), whereas the wild-type BP4 is completely cleaved (lane 4). The N-ter and C-ter cleavage fragments co-migrated as previously shown (Figure 1C and (Laursen et al, 2001)). The doublet band seen in the conditioned medium from dBP4-transfected 
A

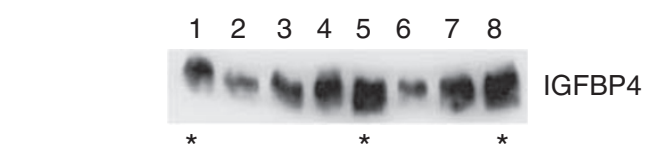

B

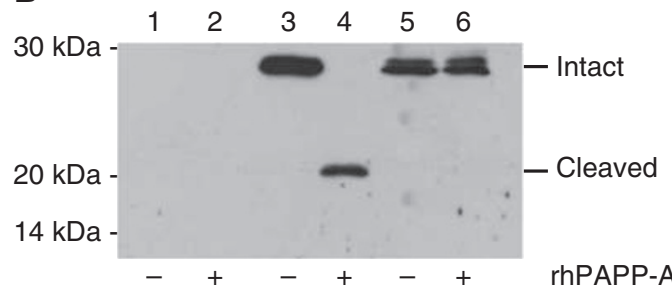

C

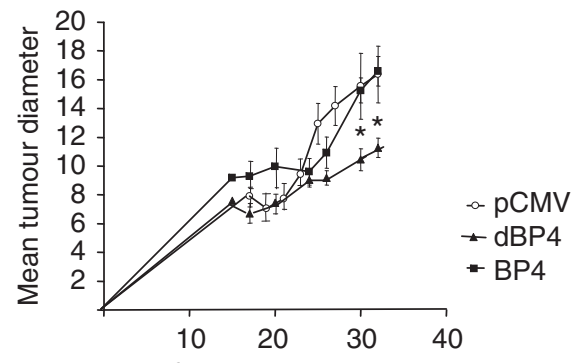

Days after tumour implantation

D

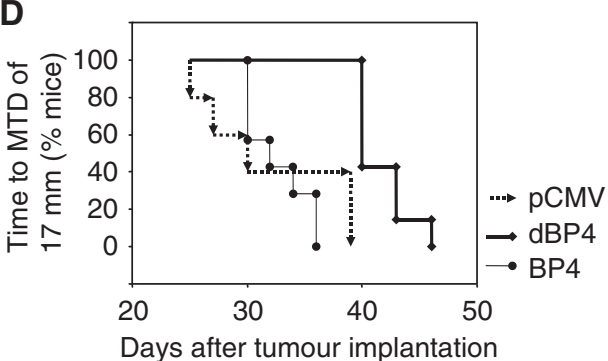

Figure 3 Protease-resistant IGFBP4 inhibits tumour growth. 4TI.2 tumour cells were transfected with control plasmid (pCMV), plasmid expressing wildtype IGFBP4 (pCMV-BP4) or plasmid expressing protease-resistant IGFBP4 (pCMV-dBP4). (A) Western blot showing IGFBP4 expression by control cells (lane I) and single cell clones expressing dBP4 (lanes 2-5) or BP4 (lanes 6-8). Clones marked with an asterisk were used for in vivo studies. (B) HEK293T cells, which do not express endogenous IGFBP4, were transfected with pCMV (lanes I + 2), pCMV-BP4 (lanes 3+4) or pCMV-dBP4 (lanes $5+6$ ). Conditioned medium was treated with rhPAPP-A in the presence of IGF2 for $24 \mathrm{~h}$ (-; untreated, +; PAPP-A-digested). Intact IGFBP4 and cleavage fragments were identified by western blot. (C) Tumour growth curve. 4TI.2 tumour cells transfected with control plasmid (pCMV), plasmid expressing wildtype IGFBP4 (pCMV-BP4) or plasmid expressing protease-resistant IGFBP4 (pCMV-dBP4) were implanted into the mammary fat pad of BALB/c mice $(n=7$ per group). Tumour diameter was measured on alternate days. Data $(n=7)$ expressed as mean \pm s.e.m. and analysed by ANOVA with LSD post hoc correction. *P $<0.05 \mathrm{dBP} 4$ vs pCMV or BP4. Data representative of two independent experiments. (D) Kaplan-Meier plot showing increased time to reach a mean tumour diameter (MTD) of $17 \mathrm{~mm}$ in mice with tumours expressing $\mathrm{dBP} 4$ relative to mice with tumours transfected with $\mathrm{pCMV}$ or BP4 $\left(\chi^{2}=16.4\right.$, $P<0.000$ I). Data representative of two independent experiments.
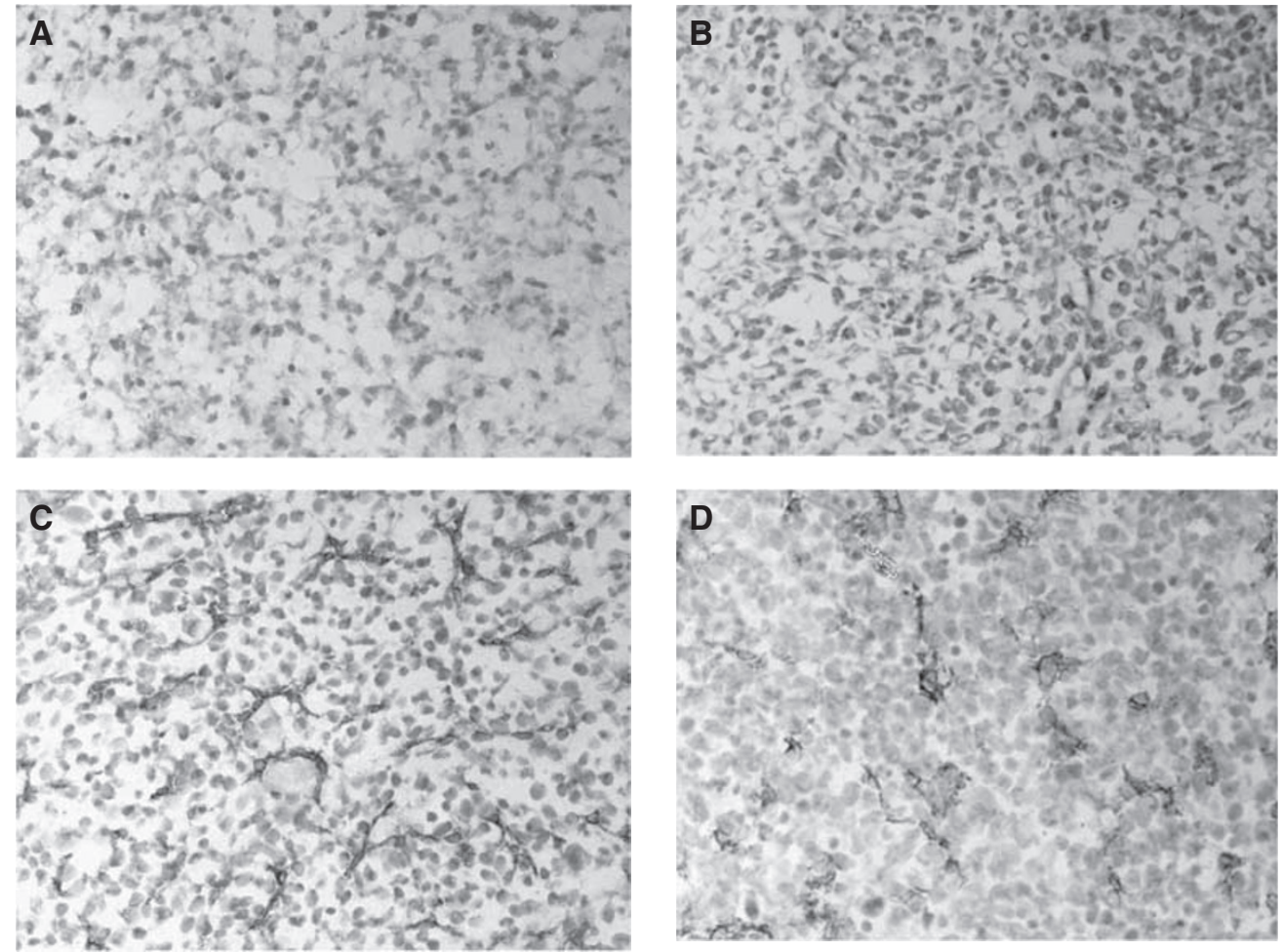

Figure 4 Angiogenesis in 4TI.2 mammary fat pad tumours. Sections were stained with anti-MECA32 to identify blood vessels. Negative control shown in (A). Representative sections stained for MECA32 from the mammary fat pad tumours transfected with (B) empty vector (pCMV), (C) plasmid expressing wild-type IGFBP4 (pCMV-BP4) or (D) plasmid expressing protease-resistant IGFBP4 (pCMV-dBP4). (Original magnification, $\times$ 400). 
HEK293 cells is probably a consequence of differential glycosylation as reported previously (Laursen et al, 2001).

4T1.2 cells transfected with pCMV, pCMV-BP4 or pCMV-dBP4 were implanted into the mammary fat pad of $\mathrm{BALB} / \mathrm{c}$ mice. After 30 days tumours transfected with pCMV-dBP4 were significantly smaller $(10.45 \pm 0.76 \mathrm{~mm})$ than tumours transfected with pCMV-BP4 $(15.26 \pm 0.87 \mathrm{~mm})$, or pCMV $(15.55 \pm 2.29 \mathrm{~mm})$ (Figure 3C). In this experiment all mice were killed when tumours in the control group reached an MTD of $17 \mathrm{~mm}$ in accordance with UKCCCR guidelines (1998). In a second experiment, time to reach an MTD of $17 \mathrm{~mm}$ was used as a surrogate end point in accordance with UKCCCR guidelines (1998). Tumours transfected with pCMV-dBP4 took significantly longer to reach an MTD of $17 \mathrm{~mm}(41.7 \pm 2.2$ days $)$ than micebearing tumours transfected with pCMV ( $32 \pm 5.9$ days) or pCMVBP4 (32.6 \pm 2.5 days) (Figure 3D).

\section{Tumour angiogenesis}

Microvessel density in the mammary fat pad tumours transfected with pCMV (empty vector), wild-type IGFBP4 (BP4) or PAPP-Aresistant IGFBP4 (dBP4) was scored following MECA32 immunohistochemistry (Figure 4). Although there was no statistically significant difference in microvessel density between the different groups ( $P=\mathrm{NS}$, ANOVA with Bonferroni post hoc correction), the vessels within tumours expressing PAPP-A-resistant IGFBP4 (D), appeared to be of poor quality, with patchy staining suggesting a discontinuous endothelium and expanded cell cytoplasm; vessels were also occluded with no lumen visible, compared with tumours transfected with pCMV (B) or pCMV-BP4 (C). Endothelial cell apoptosis was then examined using a double stain for CD31 (to identify endothelial cells) and TUNEL (to identify apoptotic cells) (Figure 5). Tumours expressing PAPP-A-resistant IGFBP4 (C) had significantly higher numbers of apoptotic endothelial cells $(6.97 \pm 3.26$ s.e.m/h.p.f.) than tumours transfected with pCMV (0.90 \pm 0.50 s.e.m/h.p.f.) or pCMV-BP-4 (1.20 \pm 0.95 s.e.m./h.p.f.) (D).

\section{DISCUSSION}

In vivo the activity of IGF is regulated by the IGF-binding proteins, which function to either enhance or inhibit the mitogenic activities of IGF1 (Jones and Clemmons, 1995). The majority of IGF is synthesised within the liver and transported in the bloodstream bound to the IGFBPs. When bound to IGFBP4, IGF1 is biologically inactive but IGFBP4 can be cleaved by the IGFBP4-specific protease, PAPP-A, to release active IGF1 (Conover et al, 2004).

4T1.2 cells expressed the IGF1R and IGFBP4, but not the IGFBP4 protease PAPP-A, although PAPP-A was expressed within 4T1.2 mammary fat pad tumours. IGFBP4 cleavage fragments were identified in 4T1.2 mammary fat pad tumour tissue but not in cultured $4 \mathrm{~T} 1.2$ cells or conditioned medium, suggesting that PAPPA within the tumours was produced by host cells. Within the tumour environment, it is likely that the secretion of IGFBP4 in the presence of the IGFBP4 protease (produced by host cells, such as fibroblasts and osteoblasts) provides a steady supply of IGF1 to the tumour to support its growth and angiogenesis. IGF1(E3R), a recombinant form of IGF1, which is resistant to IGFBP binding and therefore retains its activity even in the presence of IGFBPs, increased $4 \mathrm{~T} 1.2$ cell proliferation and production of the angiogenic factor, VEGF. Wild-type IGF1 did not increase $4 \mathrm{~T} 1.2$ cell proliferation and had no effect on VEGF expression suggesting that the IGF1 is bound by IGFBP4 (and/or other IGFBPs) secreted by the 4T1.2 cells and rendered biologically inactive, while IGF1(E3R) remains unbound and thus biologically active. In addition to its effects on 4T1.2 tumour cells, IGF1 stimulated growth of human dermal MVECs, an effect that was blocked by recombinant IGFBP4. These data indicated that IGF1 would promote angiogenesis and that IGFBP4 could block IGF1stimulated angiogenesis.

We then examined the effect of IGF1 blockade on growth of 4T1.2 mammary tumours in vivo. The approach we used was to transfect $4 \mathrm{~T} 1.2$ cells with a protease-resistant IGFBP4. The $4 \mathrm{~T} 1.2$ orthotopic model used here arose from a spontaneous mammary tumour in a $\mathrm{BALB} / \mathrm{c}$ mouse and spontaneously metastasises to lung and bone recapitulating breast tumour tissue microenvironment and cell-cell interactions (Lelekakis et al, 1999). It is therefore a clinically relevant model, which reflects the behaviour of human breast cancer. The protease-resistant IGFBP4 clone used (dBP4) was previously shown to be resistant to cleavage by a smooth muscle cell-derived protease, but its binding affinity for IGF1 was equivalent to wild-type IGFBP4 (Zhang et al, 2002). Previous studies had demonstrated that this $\mathrm{dBP} 4$ construct was resistant to cleavage by a protease present in conditioned medium from smooth muscle cells, but did not unequivocally show that the protease was PAPP-A (Zhang et al, 2002). We demonstrated that this construct was resistant to cleavage by recombinant PAPP-A. IGF will therefore remain bound to this IGFBP4 and inactive even in the presence of PAPP-A. 4T1.2 cells transfected with pCMV (empty vector), pCMV-BP4 (plasmid expressing wild-type IGFBP4) or pCMV-dBP4 (plasmid expressing protease-resistant IGFBP4) were implanted into the mammary fat pad of BALB/c mice. Tumours expressing protease-resistant IGFBP4 grew significantly more slowly than tumours transfected with pCMV or pCMV-BP4 (measured as time to reach an MTD of $17 \mathrm{~mm}$ ). As IGF1 increased VEGF production by the 4T1.2 cells and stimulated MVEC proliferation, we anticipated that an antiangiogenic effect might underlie this inhibition of tumour growth. We therefore examined microvessel density and morphology within the tumours by MECA32 staining. Although there was no statistically significant difference in vessel number in the tumours of all three groups at the time point examined, vessels in tumours expressing PAPP-Aresistant IGFBP4 were of poorer quality than in the other groups with patchy staining and occluded lumen. A similar effect was previously observed in tumours treated with the angiogenesis inhibitor, alphastatin, where vessels also had a discontinuous endothelial cell wall and occluded lumen (Staton et al, 2004). Tumour sections were then stained with CD31 and TUNEL to identify apoptotic endothelial cells. There were almost no apoptotic endothelial cells in control tumours or those expressing wild-type IGFBP4, but there were large numbers of apoptotic endothelial cells in the tumours expressing proteaseresistant IGFBP4. Our data clearly show that expression of PAPPA-resistant IGFBP4 results in endothelial cell apoptosis within the tumours and inhibition of tumour growth. Although we saw increased endothelial cell apoptosis in tumours expressing protease-resistant IGFBP4, this was not reflected in reduced microvessel density. This was probably because at the time point analysed non-transfected cells would likely predominate within the tumour with a concomitant decrease in $\mathrm{dBP} 4$ expression and regrowth of vessels.

In contrast to our findings in an orthotopic model of breast cancer where wild-type IGFBP4 had no effect on tumour growth, wild-type IGFBP4 inhibited tumour growth in non-orthotopic murine models of colon cancer and prostate cancer where transfected cells were implanted subcutaneously (Damon et al, 1998; Durai et al, 2007). However, subcutaneous expression of the PAPP-A protease may be quite different to that in either the colon or the prostate gland. Our data show that PAPP-A is present and active in both normal mammary tissue and 4T1.2 mammary fat pad tumours where the PAPP-A is produced by host cells within the tumours. Therefore, in the mammary tissue at least, the interaction between the tumour cells and associated host cells is important for PAPP-A-mediated cleavage of IGFBP4 and therefore control of IGF bioavailability and activity. The importance of using orthotopic mouse models in cancer studies has been highlighted 

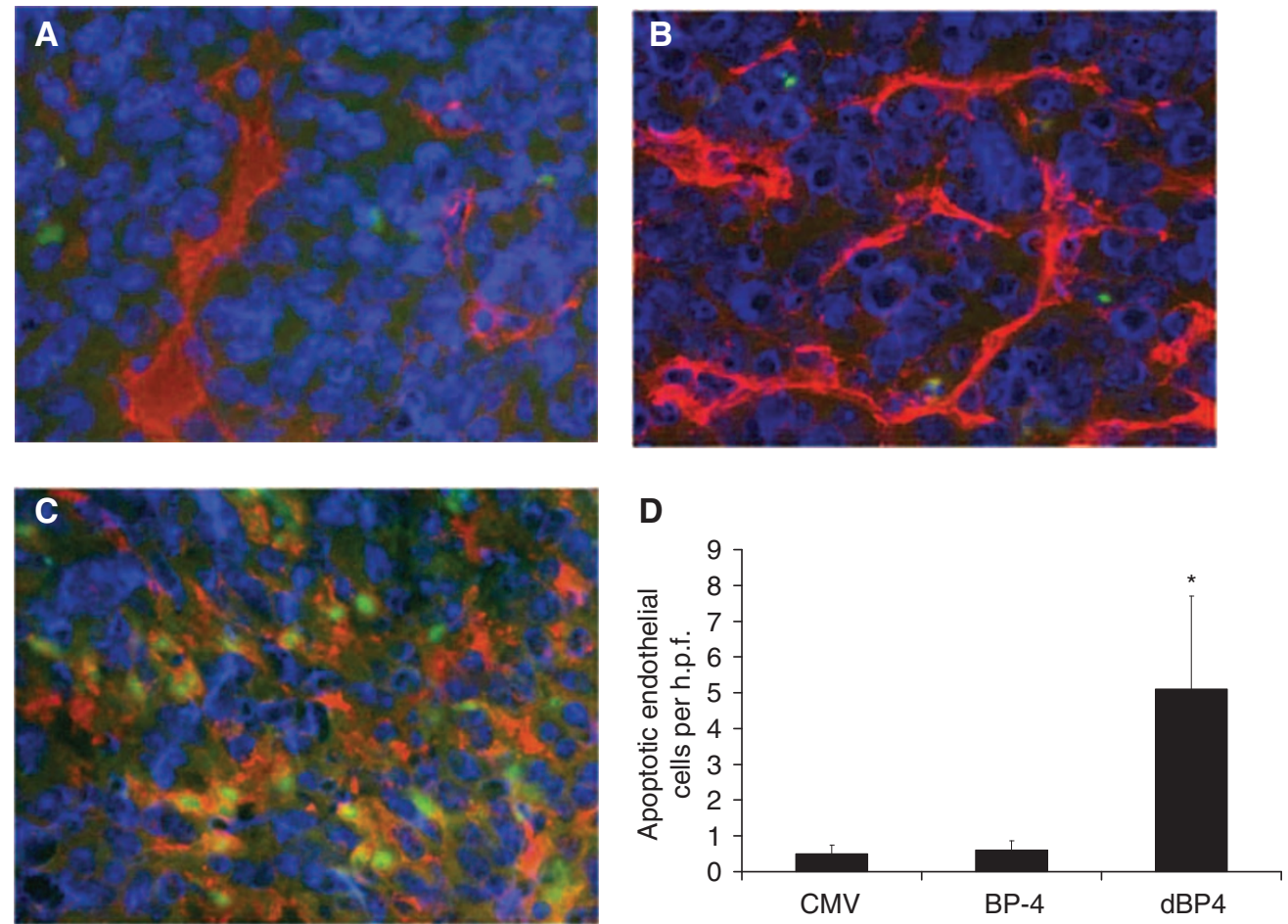

Figure 5 Protease-resistant IGFBP4 increases endothelial cell apoptosis. Sections of 4TI.2 mammary fat pad tumours transfected with (A) empty vector (pCMV), (B) plasmid expressing wild-type IGFBP4 (pCMV-BP4) or (C) plasmid expressing protease-resistant IGFBP4 (pCMV-dBP4) were stained for CD3I (to identify blood vessels), and TUNEL (to identify apoptotic cells). Red: CD3I positive, Green: TUNEL positive and Blue: nuclei stained with DAPI (original magnification $\times 400$ ). (D) Apoptotic endothelial cells were counted in five high power fields of view (h.p.f.) per section from at least three mice per group. Data expressed as mean \pm s.e.m and analysed by ANOVA with Bonferroni post hoc correction. ${ }^{*} P<0.05$ protease-resistant IGFBP4 (dBP4) vs empty vector or wild-type IGFBP4 (BP4).

recently (Fidler, 2006). Tumour microenvironment plays a critical role in tumour growth, particularly angiogenesis and metastasis, both of which are regulated by host factors as well as tumour factors (Fidler, 2003). As PAPP-A is expressed by fibroblasts and osteoblasts, host cells in and around tumours are likely to play an important role in proteolysis of IGFBP4 (Conover et al, 1993; Durham et al, 1995).

Wild-type IGFBP4 may paradoxically increase tumour growth by serving as a reservoir of IGF1. Indeed, systemic administration of wild-type IGFBP4 increased bone formation parameters (osteocalcin, alkaline phosphate) in mice by increasing IGF bioavailability (Miyakoshi et al, 2001). The approach described here - PAPP-Aresistant IGFBP4 - will inhibit IGF activity even in the presence of the PAPP-A protease and there is some evidence that PAPP-A plays a role in human breast cancer progression (Kuhajda et al, 1985).

There are a number of strategies to block IGF under investigation, some of which are in clinical trials. An antibody, $\alpha$ IR3, directed against the IGF receptor, IGF1R, blocked IGF activity and tumour growth in xenograft models of human breast cancer, but the antibody had some agonist activity and cross-reactivity with the insulin receptor (Kato et al, 1993). Insulin-like growth factor antagonists which act by blockade of interactions at the IGF1R may also significantly alter insulin action at the insulin receptor, a serious and unacceptable side effect. As multiple IGF receptors exist, targeting IGF itself is likely to be more effective than targeting IGF1R.

The IGFBPs are specific for the IGFs and should not affect insulin signalling. IGFBP2 and IGFBP3 have been examined as approaches to block IGF signalling. As the IGFBPs bind IGF with higher affinity than IGFR1, they should effectively compete with the receptor for IGF ligand binding (Clemmons, 1997). rhIGFBP3 (recombinant human IGFBP3) was shown to potentiate the activity of Herceptin against MCF7 xenografts engineered to overexpress HER2 (Jerome et al, 2006). Unlike IGFBP4, which is always inhibitory, other IGFBPs can either inhibit or potentiate IGF activity depending on the context and have IGF-independent effects as well as IGF-dependent activity. Under certain conditions IGFBP3 increased IGF-dependent cell survival and proliferation, possibly by enhanced delivery of IGF1 to IGF1R (De Mellow and Baxter, 1988). IGFBP3 acts as the major carrier of IGF1 in the circulation where it exists as a complex with the ALS (acid labile subunit). This complex acts as a reservoir of IGF1, which can be mobilised by proteolysis of IGFBP3. This complex does not cross the endothelial barrier and complex formation with ALS may impair delivery of rIGFBP3 to tumour tissue (Payet et al, 2004). We believe that our approach using a protease-resistant IGFBP4 to block IGF activity is superior to those described above, as it inactivates IGF1, is small enough $(24-32 \mathrm{kDa})$ to cross the endothelial barrier and should have a long half-life in vivo due its resistance to the PAPP-A protease. In addition to the data presented here, a protease-resistant IGFBP4 was recently shown to inhibit IGF and therefore neointimal expansion in a model of neointimal hyperplasia (Nichols et al, 2007). It is a relatively small molecule compared with antibody therapies, and hence may penetrate tumours more effectively. The data presented here showing that a protease-resistant IGFBP4 blocks IGF activity and therefore tumour growth and angiogenesis, suggests that proteaseresistant IGFBP4 may have value as a novel breast cancer treatment. We are currently investigating the therapeutic potential of recombinant protease-resistant IGFBP4 in breast cancer.

\section{ACKNOWLEDGEMENTS}

This study is based upon works supported by the Science Foundation Ireland under Grants no. 06/RFP/BIM049, 08/NSC/ 1727 and by Cancer Research Ireland under Grant CRI02HAR to 
JHH Funding was also received from the Beaumont Hospital Cancer Research and Development Trust. 4T1.2 cells were a gift from Dr Robin Anderson, Trescowthick Research Laboratories, Peter MacCallum Cancer Centre, Locked Bag 1, A'Beckett Street, Melbourne, Victoria 8006, Australia. Clones pSMP8 and pW12 were a gift from Dr James Fagin, Division of Endocrinology, University of Cincinnati College of Medicine and the Children's
Hospital Medical Center, Cincinnati, Ohio 45267-0547, USA. We thank Dr Claus Oxvig, Department of Molecular Biology, University of Aarhus, Gustav Wieds Vej 10C, DK-8000 Aarhus C, Denmark for the gift of recombinant human PAPP-A and invaluable advice and Professor Elaine Kay, Department of Pathology, Beaumont Hospital, Dublin 9, for assistance in interpreting immunohistochemistry.

\section{REFERENCES}

Bunn RC, Green LD, Overgaard MT, Oxvig C, Fowlkes JL (2004) IGFBP-4 degradation by pregnancy-associated plasma protein-A in MC3T3 osteoblasts. Biochem Biophys Res Commun 325: 698-706

Chelius D, Conover CA, Baldwin MA, Spencer EM (2000) Characterization of the enzymatic specificity of the IGF-dependent insulin-like growth factor binding protein-4 (IGFBP-4) protease. Growth Horm IGF Res 10: $360-366$

Clemmons DR (1997) Insulin-like growth factor binding proteins and their role in controlling IGF actions. Cytokine Growth Factor Rev 8: 45-62

Clemmons DR, Busby W, Clarke JB, Parker A, Duan C, Nam TJ (1998) Modifications of insulin-like growth factor binding proteins and their role in controlling IGF actions. Endocr J 45(Suppl): S1 - S8

Conover CA, Bale LK, Overgaard MT, Johnstone EW, Laursen UH, Fuchtbauer EM, Oxvig C, van Deursen J (2004) Metalloproteinase pregnancy-associated plasma protein $\mathrm{A}$ is a critical growth regulatory factor during fetal development. Development 131: 1187-1194

Conover CA, Durham SK, Zapf J, Masiarz FR, Kiefer MC (1995) Cleavage analysis of insulin-like growth factor (IGF)-dependent IGF-binding protein-4 proteolysis and expression of protease-resistant IGF-binding protein-4 mutants. I Biol Chem 270: 4395-4400

Conover CA, Kiefer MC, Zapf J (1993) Posttranslational regulation of insulin-like growth factor binding protein-4 in normal and transformed human fibroblasts. Insulin-like growth factor dependence and biological studies. J Clin Invest 91: 1129-1137

Damon SE, Maddison L, Ware JL, Plymate SR (1998) Overexpression of an inhibitory insulin-like growth factor binding protein (IGFBP), IGFBP-4, delays onset of prostate tumor formation. Endocrinology 139: 3456-3464

De Mellow JS, Baxter RC (1988) Growth hormone-dependent insulin-like growth factor (IGF) binding protein both inhibits and potentiates IGF-Istimulated DNA synthesis in human skin fibroblasts. Biochem Biophys Res Commun 156: 199-204

Durai R, Yang SY, Sales KM, Seifalian AM, Goldspink G, Winslet MC (2007) Insulin-like growth factor binding protein-4 gene therapy increases apoptosis by altering Bcl-2 and Bax proteins and decreases angiogenesis in colorectal cancer. Int J Oncol 30: 883-888

Durham SK, De Leon DD, Okazaki R, Riggs BL, Conover CA (1995) Regulation of insulin-like growth factor (IGF)-binding protein-4 availability in normal human osteoblast-like cells: role of endogenous IGFs. J Clin Endocrinol Metab 80: $104-110$

Fidler I (2006) Models for spontaneous metastasis. Cancer Res 66: 9787

Fidler IJ (2003) The pathogenesis of cancer metastasis: the 'seed and soil' hypothesis revisited. Nat Rev Cancer 3: 453-458

Fowlkes JL, Thrailkill KM, Serra DM, Nagase H (1997) Insulin-like growth factor binding protein (IGFBP) substrate zymography. A new tool to identify and characterize IGFBP-degrading proteinases. Endocrine 7: $33-36$

Hailey J, Maxwell E, Koukouras K, Bishop WR, Pachter JA, Wang Y (2002) Neutralizing anti-insulin-like growth factor receptor 1 antibodies inhibit receptor function and induce receptor degradation in tumor cells. $\mathrm{Mol}$ Cancer Ther 1: 1349-1353

Hankinson SE, Willett WC, Colditz GA, Hunter DJ, Michaud DS, Deroo B, Rosner B, Speizer FE, Pollak M (1998) Circulating concentrations of insulin-like growth factor-I and risk of breast cancer. Lancet 351: $1393-1396$

Harmey JH, Bucana CD, Lu W, Byrne AM, McDonnell S, Lynch C, Bouchier-Hayes D, Dong Z (2002) Lipopolysaccharide-induced metastatic growth is associated with increased angiogenesis, vascular permeability and tumor cell invasion. Int J Cancer 101: 415-422

Huynh HT, Tetenes E, Wallace L, Pollak M (1993) In vivo inhibition of insulin-like growth factor I gene expression by tamoxifen. Cancer Res 53: $1727-1730$
Jerome L, Alami N, Belanger S, Page V, Yu Q, Paterson J, Shiry L, Pegram M, Leyland-Jones B (2006) Recombinant human insulin-like growth factor binding protein 3 inhibits growth of human epidermal growth factor receptor-2-overexpressing breast tumors and potentiates herceptin activity in vivo. Cancer Res 66: $7245-7252$

Jones JI, Clemmons DR (1995) Insulin-like growth factors and their binding proteins: biological actions. Endocr Rev 16: 3-34

Kato H, Faria TN, Stannard B, Roberts Jr CT, LeRoith D (1993) Role of tyrosine kinase activity in signal transduction by the insulin-like growth factor-I (IGF-I) receptor. Characterization of kinase-deficient IGF-I receptors and the action of an IGF-I-mimetic antibody (alpha IR-3). J Biol Chem 268: 2655-2661

Korc-Grodzicki B, Ren N, Hilf R (1993) Insulin-like growth factor-binding proteins in $\mathrm{R} 3230 \mathrm{AC}$ mammary tumors of intact and diabetic rats. Endocrinology 133: 2362 - 2370

Kuhajda FP, Abeloff MD, Eggleston JC (1985) Pregnancy-associated plasma protein A: a clinically significant predictor of early recurrence in stage II breast carcinoma. Hum Pathol 16: 228-235

Laursen LS, Overgaard MT, Soe R, Boldt HB, Sottrup-Jensen L, Giudice LC, Conover CA, Oxvig C (2001) Pregnancy-associated plasma protein-A (PAPP-A) cleaves insulin-like growth factor binding protein (IGFBP)-5 independent of IGF: implications for the mechanism of IGFBP-4 proteolysis by PAPP-A. FEBS Lett 504: 36-40

Lawrence JB, Oxvig C, Overgaard MT, Sottrup-Jensen L, Gleich GJ, Hays LG, Yates III JR, Conover CA (1999) The insulin-like growth factor (IGF)dependent IGF binding protein-4 protease secreted by human fibroblasts is pregnancy-associated plasma protein-A. Proc Natl Acad Sci USA 96: $3149-3153$

Lelekakis M, Moseley JM, Martin TJ, Hards D, Williams E, Ho P, Lowen D, Javni J, Miller FR, Slavin J, Anderson RL (1999) A novel orthotopic model of breast cancer metastasis to bone. Clin Exp Metastasis 17: $163-170$

LeRoith D, Werner H, Beitner-Johnson D, Roberts Jr CT (1995) Molecular and cellular aspects of the insulin-like growth factor I receptor. Endocr Rev 16: $143-163$

Lewinski A, Marcinkowska M, Brzezianska E, Jeziorowska A, Wloch J, Brzezinski J (2004) Expression of insulin-like growth factor I (IGF-I) gene and of genes for IGF-binding proteins 1, 2, 3, 4 (IGFBP-1-IGFBP-4) in non-neoplastic human thyroid cells and in certain human thyroid cancers. Effect of exogenous IGF-I on this expression. Endocr Res 30: $47-59$

Miyakoshi N, Qin X, Kasukawa Y, Richman C, Srivastava AK, Baylink DJ, Mohan S (2001) Systemic administration of insulin-like growth factor (IGF)-binding protein-4 (IGFBP-4) increases bone formation parameters in mice by increasing IGF bioavailability via an IGFBP-4 proteasedependent mechanism. Endocrinology 142: 2641 - 2648

Nichols TC, Busby Jr WH, Merricks E, Sipos J, Rowland M, Sitko K, Clemmons DR (2007) Protease-resistant insulin-like growth factor (IGF)binding protein-4 inhibits IGF-I actions and neointimal expansion in a porcine model of neointimal hyperplasia. Endocrinology 148: 5002-5010 Overgaard MT, Haaning J, Boldt HB, Olsen IM, Laursen LS, Christiansen M, Gleich GJ, Sottrup-Jensen L, Conover CA, Oxvig C (2000) Expression of recombinant human pregnancy-associated plasma protein-A and identification of the proform of eosinophil major basic protein as its physiological inhibitor. J Biol Chem 275: 31128-31133

Payet LD, Firth SM, Baxter RC (2004) The role of the acid-labile subunit in regulating insulin-like growth factor transport across human umbilical vein endothelial cell monolayers. J Clin Endocrinol Metab 89: 2382 - 2389

Peyrat JP, Bonneterre J, Hecquet B, Vennin P, Louchez MM, Fournier C, Lefebvre J, Demaille A (1993) Plasma insulin-like growth factor-1 (IGF-1) concentrations in human breast cancer. Eur I Cancer 29A: 492-497 
Rehault S, Monget P, Mazerbourg S, Tremblay R, Gutman N, Gauthier F, Moreau T (2001) Insulin-like growth factor binding proteins (IGFBPs) as potential physiological substrates for human kallikreins hK2 and hK3. Eur J Biochem 268: 2960-2968

Saltiel AR, Kahn CR (2001) Insulin signalling and the regulation of glucose and lipid metabolism. Nature 414: 799-806

Staton CA, Brown NJ, Rodgers GR, Corke KP, Tazzyman S, Underwood JC, Lewis CE (2004) Alphastatin, a 24-amino acid fragment of human fibrinogen, is a potent new inhibitor of activated endothelial cells in vitro and in vivo. Blood 103: 601-606
United Kingdom Co-ordinating Committee on Cancer Research (UKCCCR) (1998) Guidelines for the Welfare of Animals in Experimental Neoplasia (Second Edition). Br J Cancer 77: 1 - 10

Wu WC, Kao YH, Chung CH (2004) Effects of growth-factor combinations on vascular endothelial cell growth in vitro. J Ocul Pharmacol Ther 20: $554-562$

Zhang M, Smith EP, Kuroda H, Banach W, Chernausek SD, Fagin JA (2002) Targeted expression of a protease-resistant IGFBP-4 mutant in smooth muscle of transgenic mice results in IGFBP-4 stabilization and smooth muscle hypotrophy. J Biol Chem 277: 21285-21290 